\title{
When demand outstrips supply: A Christian view of the ethics of healthcare resource allocation during the COVID-19 pandemic
}

\author{
James Haslam ${ }^{a}$ and Melody Redman ${ }^{b}$ \\ ${ }^{a}$ MBBS, Consultant in Anaesthesia \& Intensive Care Medicine at Salisbury NHS Foundation Trust, Wiltshire, UK \\ ${ }^{b}$ MBBS, Paediatric Trainee \& Leadership Fellow, Sheffield, UK
}

\begin{abstract}
The coronavirus (COVID-19) pandemic presents the greatest challenge to global healthcare systems in living memory. This article deals with the ethics of rationing the supply of scarce healthcare resources, such as ventilators, during periods of high demand, such as the current pandemic. Existing ethical guidelines and commentaries are cited and critiqued from a Christian ethics viewpoint.
\end{abstract}

Key Words: coronavirus, COVID-19, pandemic, bioethics, Christian ethics, rationing.

\section{Introduction}

As doctors working in the United Kingdom's National Health Service (NHS), a well-resourced and integrated European healthcare system, we approach the subject of healthcare rationing with a degree of humility. We are yet to work in a healthcare setting in a developing nation, where agonising decisions around resource allocation can be a daily occurrence. On one level, we have minimal experience of rationing essential resources for our patients. But, after deeper reflection, perhaps those of us who work as doctors in the NHS do have at least some expertise in resource allocation?

We may not sit on the Donation Ethics Committee, deciding which patient on the transplant list is most deserving of the latest precious organ:

... the single mother?

... the recovering alcoholic with liver disease?

... the university student?

... the doctor?

We do, however, triage patients all the time. The word triage is derived from the 14th-century French verb trier, which means to pick or sort. ${ }^{1}$ When we are deciding which patient to see next on our list of referrals, do we decide purely on a "first-come, first- served" basis, or do we prioritise on the basis of need? When the crash bleep goes off for a bleeding periarrest patient, do we leave them to exsanguinate whilst we continue our clinic, or do we prioritise on the basis of urgency? When we apply for funding to give a novel treatment, we do so on the basis we believe a particular patient in our care meets the criteria to benefit from that treatment and that such benefit will offset the substantial cost. If resources were truly unlimited, perhaps all patients admitted to hospital would have a nurse:patient ratio of $1: 1$, as guidelines state Level 3 patients should on the Intensive Care Unit (ICU). The reality is that resources are routinely allocated to different patients variably. The question is: on what basis should limited healthcare resources be allocated?

When asked, what is the greatest commandment:

Jesus replied: "'Love the Lord your God with all your heart and with all your soul and with all your mind.' This is the first and greatest commandment. And the second is like it: 'Love your neighbour as yourself.", (Mt. 22:37-39)2

These are fundamental truths by which we make our day-to-day decisions, trivial or important. Loving our neighbour may look quite different from one 
person to the next, based on clinical need and health status. Yet love must remain at the heart of all our decisions. What does this look like in practice?

The COVID-19 coronavirus pandemic brings this question into sharp focus. The demand for intensive life-saving resources from seriously unwell, and even critically ill, patients is rising rapidly in countries all around the world. Managing this demand has involved measures such as testing, contact tracing, quarantining, and social distancing to "flatten the curve."

There are many examples in scripture of increasing resources in times of challenge through faith and prayer (Mt. 14:19; 2 Ki. 4:1-7), recruiting more workers (Mt. 9:37-38), and training and releasing new leaders (Nu. 11:16-17; Lk. 10:1). On the healthcare supply side of the COVID-19 response, there has been a commendable concerted effort from the UK Government to delay elective activity and increase capacity, including staff measures such as:

1. Bringing back retired doctors and nurses.

2. Recruiting final year medical and nursing students.

3. Diverting staff from other specialities, often by closing or delaying non-essential activities.

Infrastructure and equipment supply side capacity increases include:

1. Building or converting new hospitals such as the ExCel Nightingale Hospital.

2. Creating more high care capacity, for example by increasing use of continuous positive airway pressure (CPAP) devices.

3. Re-deploying ventilators from the operating theatre and commissioning new ventilators to provide more ventilated ICU beds. ${ }^{3}$

4. Increasing financial and other resources.

Despite these admirable efforts, our supply of healthcare resources is being outstripped in certain locations and may yet be even more dramatically so. ${ }^{4}$ This will inevitably result in some very challenging decisions around rationing, involving serious ethical dilemmas.

The British Medical Association (BMA) has recently produced guidance around the ethical issues presented by the COVID-19 pandemic. ${ }^{5}$ The National
Institute for Health and Care Excellence (NICE) has also produced a rapid guideline for adult critical care during the pandemic, which includes guidance for decision-making around escalation. ${ }^{6}$ In addition, the Royal College of Physicians (RCP) has issued guidance, in conjunction with other stakeholders such as the General Medical Council, the Faculty of Intensive Care Medicine, the Intensive Care Society, and royal colleges and faculties. ${ }^{7}$ As Christian doctors, we must consider how we can respond to the ethical challenges posed. Here we will attempt to consider some of the issues involved and how to think about them biblically, using Beauchamp and Childress' widely recognised four pillars of medical ethics as a framework. $^{8}$

\section{Respect for patient autonomy}

It is clear that if a patient has capacity and refuses escalation in care, even life-sustaining treatments, these cannot be forced on them, even if this seems unwise. ${ }^{9}$ However, if a patient insists they should be for full escalation, that does not necessarily mean they are a suitable candidate or that they should be offered all potentially available treatments. Doctors are not obliged to offer treatments that they consider are not in their patient's best interests. It can be clinically appropriate to withhold certain treatments that are unlikely to be of benefit. ${ }^{10}$ Unfortunately, in some cases, intensive treatment may convert what could be a "good death" into a "bad death." Dying in the more impersonal context of an ICU, or even in hospital at all, is an outcome that many patients would wish to avoid. With this in mind, some patients, particularly those frail and elderly, might choose not to be treated in hospital but to stay at home with their family with the support of high-quality palliative care or "hospice at home" teams. This may allow patients a more natural death, in the comfort of their own home, and in the company of those they love.

\section{Beneficence - maximising benefit with good stewardship of resources}

As Christian healthcare workers, we are called to be good stewards of our resources - see, for example, the Parable of the Talents (Mt. 25:14-30). However, utilitarianism ${ }^{11}$ — "the greatest good for the greatest number" - often makes us deeply uncomfortable. The ends do not necessarily justify the means; motives, 
virtue, and other moral principles can be neglected ${ }^{12}$ in this approach to ethics that often emphasizes the value to society over the paramount value of each individual human life ("ends in themselves" - Immanuel Kant). Yet, the COVID-19 crisis is an example of an extreme circumstance with an overwhelming need and limited resources where a utilitarian ethic may be justified. Dr David Stephens is helpful here:

You are forced into using a utilitarian ethic decision-making process under these conditions:

- There are limited resources.

- There are no moral absolutes for or against an action ...

- You know your moral duty but are not sure how to fulfil it ...

- There is a conflict between two moral duties and both cannot be fulfilled ...

- You must prioritize duties ...

When you are forced to employ a utilitarian ethic, you constantly re-evaluate your allocation decisions based on changing circumstances. ${ }^{13}$

We know that we have limited and finite resources, and healthcare has to be rationed to some extent; we have seen in many areas already the postponement of many routine and elective services. Therefore, it seems reasonable where resources are insufficient, to prioritise access to intensive interventions for those who are more likely to benefit. Ultimately, it is the application of this principle which is most challenging; as our knowledge about COVID19 is patchy but expanding, we may find ourselves making decisions about prognoses without feeling we have the full information at our disposal. Yet making no decisions at all carries even greater potential for harm.

It is important to clarify here that we are only endorsing a form of "soft" utilitarianism in these extreme circumstances - what we might consider an emergency stewardship ethic in these extraordinary times. We are not, however, endorsing the "hard" form of classic utilitarianism which depends on a "hedonic calculus" where a summation is made of the positive benefits of an action and then a subtraction of all the negative consequences. This mathematical approach to ethics can lead to all kinds of abhorrent acts, such as organ donation euthanasia, which is anathema to us as Christians.

There are drawbacks with even this "soft" form utilitarianism:

Although relevant, this specification of doing the greatest good for the greatest number is inadequate because it ignores other ethically relevant considerations. For example, it is also relevant to consider the number of years of life saved. The moral intuition of many people would support prioritizing a patient who stands to otherwise lose 40 years of life, compared with one with a chronic illness that will in all likelihood result in death within a few years .. Persons who have essential responsibilities in saving lives during the pandemic, such as health care workers and first responders, also deserve heightened priority. The prioritization is not because these individuals are more intrinsically worthy but because of their instrumental value in saving others. ${ }^{14}$

We will address the prioritisation of certain categories of people later on. The authors of this article go on to advocate an ethical approach which incorporates multiple criteria into a single integrated framework ...

. . . based on (1) patients' likelihood of surviving to hospital discharge, assessed with an objective measure of acute illness severity; and (2) patients' likelihood of achieving longer-term survival based on the presence or absence of comorbid conditions that influence survival. ${ }^{14}$

This framework could be adapted over time, depending on the resource capacity, shifting evidence base, and the context in question. ${ }^{15}$

To summarise, the overarching priority when making a decision about who should receive treatment during this crisis is: how likely a person is to survive and the speed of anticipated benefit. Relevant factors include: 
- Severity of acute illness

- Presence and severity of comorbidity

- Frailty or, where clinically relevant, age ${ }^{16}$

This brings us to prognostication and certainty. Doctors vary in their ability to prognosticate likely outcomes; achieving a high degree of certainty in prognostication is fraught with difficulty. We must approach this with humility, using robust tools to help us identify disease severity (such as the Sequential Organ Failure Assessment (SOFA) score) with an extensive evidence base ${ }^{17}$ to assist us. Tools also exist to help us recognise when our patients are nearing the end of their lives. ${ }^{18}$

The Word of God repeatedly commands us to be compassionate, just as our Heavenly Father is compassionate:

Finally, all of you, be like-minded, be sympathetic, love one another, be compassionate and humble. (1 Pt. 3:8)

We know that healthcare workers are particularly susceptible to "compassion fatigue," 19 and some of us may have seen this in ourselves or others. But despite increasing stress and pressure in this time, the command remains. As Christians, now is a time to receive the compassion and comfort of the Lord so that we may pass it on to those around us (2 Co. 1:3-4). From that starting point, how can we identify ways to help prevent compassion fatigue in ourselves and those around us during this time of crisis? We should acknowledge the moral distress that rationing in the context of a pandemic will cause healthcare teams and should look to model what it means to promote wellbeing in our colleagues, as well as our patients. This is a complex area and we recommend spending some time reading ${ }^{20}$ and praying around this topic.

\section{Distributive justice - ensuring impartiality, equality and fairness}

Fairness in healthcare resource allocation could be achieved by random selection, such as a lottery, or by "first-come, first-served" allocation, but would mean that people who happen to get sick later on (perhaps because of their strict adherence to public health recommendations) are excluded from treatment, worsening outcomes without improving fairness. ${ }^{15}$
As Christians, we affirm that all people have intrinsic value and significance, being made in the very image of God (Gn. 1:27), and are equally worthy of care. One of the greatest pleasures of being part of Team NHS is that this truth is widely celebrated three of the six values in the NHS constitution are "everyone counts," "compassion," and "respect and dignity." 21

The Government introduced an ethical framework for decision making for pandemic influenza, which was revised in 2017..$^{22}$ It is a respectable framework and appropriately recognises: "everyone matters equally" and "people with an equal chance of benefiting from health or social care resources should have an equal chance of receiving them." However, equality is not the same as uniformity; that all patients are equal does not mean they should all be treated the same. Hippocrates' ancient adage comes to mind:

Cure sometimes, treat often, comfort always.

In our view, the most controversial aspect of the BMA guidance is the section entitled, "Maintaining essential services." It argues for prioritising certain groups of people according to their utility to society, for example those who work in essential services. Rather than doctors making these decisions, it argues this is a role for Government.

How about this thought experiment? Three patients are in need of the last ventilator: one is a Government Minister; one is an experienced critical care nurse; and the other is a prisoner, a convicted paedophile. Who would you choose?

The NHS depends on an unwritten social contract between the population and the service. Every year the population provides a large sum from general taxation in the understanding that the service will provide care in a fair, just, and non-discriminatory way. To give preferential care to those with higher status, whether VIPs or key workers, would prove intensely unpopular and socially destabilising. The long-term damage to the public's attitude and trust in the NHS may be far worse than the short-term benefit in saving the lives of a small number of prioritised individuals. The BMA guidance even recognises that, "decision-makers could face criticism for discriminating between individuals on the basis of social, rather than solely medical, factors." 
So, is the answer simply not to discriminate in this way at all? God's creation blessings are given indiscriminately, to the "just" and the "unjust:"

\section{But I tell you, love your enemies and pray for those who persecute you, that you may be the children of your Father in heaven. He causes his sun to rise on the evil and the good, and sends rain on the righteous and the unrighteous. (Mt. 5:44-45)}

This ethic is the underpinning of conceptions of justice within all societies based on the JudaeoChristian tradition. Justice becomes corrupted if it discriminates in favour of some lives over other lives. Throughout scripture, in different contexts, we see that all people are of equal worth, and we should not favour individuals based on their social (Ga. 3:28), financial (Jm. 2:1-9), or other status — our God abhors favouritism and loves impartiality (Pr. 24:23; Rm. $2: 11$; Lk 14:12-14). Indeed, we are called to be advocates of the vulnerable (Pr. 31:8-9).

The RCP ethical guidance, reassuringly, makes this anti-discriminatory approach more explicit:

Treatment should be provided, irrespective of the individual's background (e.g. disability), where it is considered that it will help the patient survive and not harm their long-term health and wellbeing. ${ }^{7}$

Consideration also needs to be made for access of non-COVID-19 patients to scarce healthcare resources. For example, how do we care for those requiring urgent and risky cancer treatments when our hospital resources are close to exhaustion? These are very difficult challenges and we need to pray for wisdom.

\section{Non-maleficence - minimising harm}

Consideration of when it may be appropriate to withdraw life-sustaining treatments, including invasive ventilation, in those who deteriorate despite it or have failed to respond, will also be important during this crisis. Decisions around withdrawal of life-sustaining treatments are made frequently in an ICU setting on clinical grounds of futility. Withdrawal of treatment is not morally equivalent to intentional killing. ${ }^{10}$ In those circumstances, death is already in the room, and allowing a death to take place is not the same as causing death. Perhaps, during this COVID-19 crisis, decisions around withdrawal may, out of necessity, occur sooner than would happen under normal circumstances and on grounds of resources if there is ongoing demand for scarce lifesaving assets such as ventilators for use in patients who are more likely to benefit. BMA guidance states:

Health professionals may be obliged to withdraw treatment from some patients to enable treatment of other patients with a higher survival probability. This may involve withdrawing treatment from an individual who is stable or even improving but whose objective assessment indicates a worse prognosis than another patient who requires the same resource. ${ }^{5}$

These kinds of existentially burdensome decisions are fairly unprecedented in well-resourced healthcare systems and, in addition to potential legal ramifications, ${ }^{23}$ will be emotionally, morally, and spiritually distressing for those clinicians having to make and be made accountable for them. As a consequence of this, it has been advocated that complex decisions around rationing should be made in discussion with a second opinion and even by committee:

[W]hen a hospital is placed in the unavoidable but tragic role of making decisions that may harm some patients, the use of a committee removes the weight of these choices from any one individual, spreading the burden among all members of the committee, whose broader responsibility is to save the most lives. ${ }^{24}$

One of our institutions has convened a Clinical Ethics Committee which will meet regularly to aid clinicians with these more complex and burdensome decisions. We are planning a $24 / 7$ on-call Clinical Ethics rota for telephone support during this current crisis. Is this something you could initiate or engage with in your institution? 


\section{Conclusion}

This COVID-19 pandemic provides a clarion call to pray for clinicians, managers, politicians, and all involved in the response. We should pray for new solutions, innovations, and technologies to support healthcare delivery and an end to this challenging crisis.

Ultimately, we should seek wisdom from the Lord (Jm. 1:5). We want you to know that we, our families, and our wider Church family all across the world are praying for you and other healthcare professionals all around the globe. We must endeavour to be good stewards whilst also lobbying for sufficient resources. Throughout, we must strive to affirm that compassion is key, all people are equal, and all are worthy of care.

Further thought-provoking resources are available from the Royal College of Physicians:

\section{https://www.criticalcarenice.org.uk/clinical- guidelines}

\section{References}

1. Edwards M. Triage. Lancet. 2009;373(9674):1515. https://doi.org/10.1016/S0140-6736(09)60843-6.

2. All Scripture passages quoted from the New International Version (NIV), 2011.

3. As we write, national guidance is to double and plan to more than quadruple Intensive Care bed capacity.

4. Ives J. Coronavirus may force UK doctors to decide who they'll save [Internet]. The Guardian. 2020 Mar 14. Available from:

https://www.theguardian.com/commentisfree/2020/m ar/14/coronavirus-outbreak-older-people-doctorstreatment-ethics.

5. COVID-19 - ethical issues. A guidance note [Internet]. British Medical Association. 2020 Apr 1. Available from:

https://www.bma.org.uk/media/2226/bma-covid-19ethics-guidance.pdf.

6. COVID-19 rapid guideline: critical care in adults [Internet]. National Institute for Health and Care Excellence. 2020 Mar 20. Available from: https://www.nice.org.uk/guidance/ng159.

7. Ethical dimensions of COVID-19 for frontline staff [Internet]. Royal College of Physicians. 2020 Apr 2. Available from:

https://www.rcplondon.ac.uk/news/ethical-guidancepublished-frontline-staff-dealing-pandemic.

8. Beauchamp TL, Childress JF. Principles of biomedical ethics. 5th rev. ed. New York: Oxford University Press; 2001.

9. Treatment and care towards the end of life: good practice in decision making [Internet]. General Medical Council. 2010 Jul 1. Available from: https://www.gmc-uk.org/ethical-guidance/ethicalguidance-for-doctors/treatment-and-care-towards-theend-of-life/principles.

10. Haslam J. CMF File 62: Withholding and withdrawing medical treatment [Internet]. Christian Medical Fellowship. 2017. Available from: https://admin.cmf.org.uk/pdf/cmffiles/62_withholdin g_medical treatment.pdf.

11. Bentham J. An introduction to the principles of morals and legislation (1789). Garden City, NJ: Doubleday; 1961.

12. Response from CMF to NICE on their draft guidelines on social value judgements [Internet]. Christian Medical Fellowship. 2005 Jun 30. Available from:

https://www.cmf.org.uk/advocacy/submissions/?id=3 8.

13. Stevens D. The ethical approach to limited resources. In: A Christian healthcare worker's response to COVID-19 [Internet]. Medical Missions. 2020. Available from:

https://www.medicalmissions.com/coronavirus.

14. White DB, Lo B. A framework for rationing ventilators and critical care beds during the COVID19 pandemic. JAMA [Internet]. 2020 Mar 27. https://doi.org/10.1001/jama.2020.5046.

15. Emanuel EJ, Persad G, Upshur R, Thome B, Parker M, Glickman A, et al. Fair allocation of scarce medical resources in the time of Covid-19. NEJM [Internet]. 2020 Mar 23. https://doi.org/10.1056/nejmsb2005114.

16. Coulson-Smith P, Lucassen A. Clinical ethics guidance during the COVID-19 pandemic. Paper presented at: University Hospital Southampton Clinical Ethics Committee. 2020 Mar 30; Southampton, UK.

17. For example, Report on 775 patients critically ill with COVID-19 [Internet]. Intensive Care National Audit \& Research Centre. 2020 Mar 27. Available from: https://www.icnarc.org/About/LatestNews/2020/03/27/Report-On-775-Patients-CriticallyIll-With-Covid-19.

18. See https://www.goldstandardsframework.org.uk/ or https://www.spict.org.uk/.

19. Cocker F, Joss N. Compassion fatigue among healthcare, emergency and community service workers: a systematic review. Int J Environ Res Public Health. 2016;13(6):618. https://doi.org/10.3390/ijerph13060618. 
20. Peppiatt P. Too tired to care. In: Spotlight [Internet]. Christian Medical Fellowship. 2018 Spring.

Available from:

https://www.cmf.org.uk/resources/publications/conte $\underline{\mathrm{nt} / \text { ? context }=\text { article\&id }=26779}$.

21. UK Government [Internet]. The NHS constitution for England [updated 2015 Oct 14; cited 2020 Apr 3]. Available from: https://www.gov.uk/government/publications/thenhs-constitution-for-england/the-nhs-constitution-forengland.

22. UK Government [Internet]. Pandemic flu: ethical framework [cited 2020 Apr 3]. 2013 Feb 20 [updated 2017 Nov 24]. Available from: https://www.gov.uk/guidance/pandemic-flu\#thicalframework.

23. Intensive Care Society. Legal and Ethical Advisory Group (LEAG) statement: statement on legal liabilities of clinicians as individuals during coronavirus pandemic [Internet]. 2020 Mar 31 [cited 2020 Apr 3]. Available from:

http://ics.informz.net/z/cjUucD9taT03ODY4NzM0Jn A9MSZ1PTgwOTM0MDc4OCZsaT02NDQwMzc3 OA/index.html.

24. Truog RD, et al. The toughest triage - allocating ventilators in a pandemic. NEJM [Internet]. 2020 Mar 23. https://doi.org/10.1056/nejmp2005689.

Competing Interests: None declared.

Acknowledgements: This paper has been previously published as a Briefing Paper by Christian Medical Fellowship (CMF), UK. 3 April 2020.

Correspondence: Dr. James Haslam, Wiltshire, UK. james.haslam@nhs.net

Cite this article as: Haslam J, Redman M. When demand outstrips supply: A Christian view of the ethics of healthcare resource allocation during the COVID-19 pandemic. Christian Journal for Global Health. April 2020; 7(1):13-19. https://doi.org/10.15566/cigh.v7i1.369

(C) Authors. This is an open-access article distributed under the terms of the Creative Commons Attribution License, which permits unrestricted use, distribution, and reproduction in any medium, provided the original author and source are properly cited. To view a copy of the license, visit http://creativecommons.org/licenses/by/4.0/ 